\title{
Anticancer Drug-Induced Epithelial-Mesenchymal Transition via p53/miR-34a axis in A549/ABCA3 Cells
}

\author{
Ayano Yamamoto, Masashi Kawami, Takashi Konaka, Shinnosuke Takenaka, Ryoko Yumoto, Mikihisa Takano \\ Department of Pharmaceutics and Therapeutics, Graduate School of Biomedical \& Health Sciences, Hiroshima \\ University, 1-2-3 Kasumi, Minami-ku, Hiroshima 734-8553, Japan.
}

Received, July 25, 2019; Revised, September 30, 2019; Accepted, October 4, 2019; Published, October 7, 2019.

\begin{abstract}
PURPOSE. Several anticancer drugs including bleomycin (BLM) and methotrexate (MTX) cause serious lung diseases such as pulmonary fibrosis. Although evidences showing the association of epithelial-mesenchymal transition (EMT) with pulmonary fibrosis are increasing, the mechanism underlying anticancer drug-induced EMT has been poorly understood. On the other hand, miR-34a, a non-coding small RNA, has been highlighted as a key factor to regulate EMT in lung. In this study, we elucidated the role of miR-34a in anticancer drug-induced EMT using A549/ABCA3 cells as a novel type II alveolar epithelium model. METHODS. Expression levels of $\alpha$-smooth muscle actin ( $\alpha$-SMA) mRNA, miR-34a, and p53 were evaluated by real-time PCR and western blot analysis, respectively. RESULTS. BLM and MTX induced EMT-like morphological changes and increase in mRNA expression level of $\alpha$-SMA, an EMT marker. Also, both drugs increased the expression level of miR-34a. Furthermore, mRNA expression level of $\alpha$-SMA was enhanced by introduction of miR-34a mimic into A549/ABCA3 cells. To examine the mechanism underlying drug-induced enhancement of miR-34a expression, we focused on p53/miR-34a axis. Both drugs upregulated protein expression of $\mathrm{p} 53$, an inducer of miR-34a, as well as phosphorylation of Ser15 in p53. CONCLUSIONS. These findings indicated that $\mathrm{p} 53 / \mathrm{miR}-34 \mathrm{a}$ axis may contribute to anticancer drug-induced EMT in type II alveolar epithelial cells.
\end{abstract}

\section{INTRODUCTION}

There are increasing drugs with capacity of inducing serious cytotoxic effects on lung such as pulmonary fibrosis as their adverse effects. In particular, anticancer drugs including bleomycin (BLM) (1) and methotrexate (MTX) (2) have been reported to induce severe lung diseases such as acute interstitial pneumonia and progressive pulmonary fibrosis. Although these serious pulmonary diseases carry high mortality rates, development of the effective treatment has not been achieved, partly due to poor understanding of the drug-induced lung injury.

Recently, there are several suggested schemes concerning pathogenesis of serious pulmonary diseases such as idiopathic pulmonary fibrosis (IPF) (3). In these schemes, excessive extracellular matrix (ECM) plays a crucial role in development of pathogenic lung form. ECM is mainly produced by myofibroblasts, which are derived from fibroblasts showing profibrotic phenotype $(4,5)$. When lung injury occurs, on the other hand, myofibroblasts are also generated from injured type II alveolar epithelial cells via epithelial-mesenchymal transition (EMT) process (6). Therefore, EMT contributes to development of pulmonary fibrosis $(7,8)$, and may be considered to be a possible therapeutic target to prevent the drug-induced lung injury.
MicroRNAs (miRNA) are small single-stranded non-coding RNA of approximately 22 nucleotides and regulate post-transcriptional activity of their targeted genes by binding complementarily to the 3 ' untranslated regions (9). Current studies have demonstrated that a number of miRNAs have positive or negative effects on IPF via complicated transcriptional regulations (10). In particular, miR200 family such as miR-200b and miR-200c inhibits EMT in RLE-6TN cells, by downregulating the expression of several EMT inducing factors including zinc finger E-box-binding homeobox (ZEB) $1 / 2$ (11). On the other hand, miR-199a stimulates fibroblasts in response to transforming growth factor (TGF)- $\beta 1$ via inhibitory effect on caveolin 1, a negative regulator of TGF- $\beta$ signaling pathway (12). Thus, certain miRNAs would be considerable biomarkers or therapeutic targets for EMT-related diseases.

In the lung, EMT occurs in type II alveolar epithelial cells, as evidenced by several reports using human primary type II alveolar epithelial cells and lungs of patients with IPF $(6,13)$.

\footnotetext{
Corresponding Author: Prof. Mikihisa Takano, Department of Pharmaceutics and Therapeutics, Graduate School of Biomedical \& Health Sciences, Hiroshima University, 1-2-3 Kasumi, Minami-ku, Hiroshima 734-8553, Japan; E-mail: takanom@hiroshima-u.ac.jp
} 
So far, we established RLE/Abca3 cells by introducing Abca3 gene into RLE-6TN cells (ratderived alveolar epithelial cells), and mRNA expression levels of several type II alveolar epithelial cell markers such as peptide transporter 2 (PEPT2) and formation of lamellar bodies were higher in RLE/Abca3 cells than those in the wildtype cells (14). In addition, we found that BLM and MTX could induce EMT, and miR-34a upregulation was observed in parallel with drug-induced EMT (14, 15). In this study, we attempted to establish a novel type II alveolar epithelial cell line, A549/ABCA3 cells, by introducing ABCA3 gene into A549 cell line like the case of RLE/Abca3 cells. Using this cell line, we aimed to clarify the mechanism underlying drug-induced EMT focusing on miR-34a. On the other hand, it has been reported that p53 plays a crucial role in regulation of miR-34a (16). In addition, anticancer drugs such as BLM and MTX are well-known to stimulate p53 activity $(17,18)$. However, these findings were independently reported, and evidence showing the relationship between drug-induced EMT and p53/miR-34a axis is still lacking. Therefore, we also aimed to clarify the role of p53/miR-34a axis in drug-induced EMT using A549/ABCA3 cells.

\section{MATERIALS and METHODS}

\section{Materials}

BLM was purchased from TOKYO CHEMICAL INDUSTRY CO., LTD. (Tokyo, Japan). MTX and PTX were purchased from Wako Pure Chemical Ind. (Osaka, Japan). LysoTracker ${ }^{\circledR}$ Red as a selective fluorescent probe for intracellular lipid droplets in lamellar bodies was purchased from Life Technologies (Carlsbad, CA, USA). All the other chemicals used for the experiments were of the highest purity that was commercially available.

\section{Establishment of A549/ABCA3 cells and the cell culture}

Full-length human ABCA3 gene (accession No. NM_001089) was constructed from two separated fragments, A and B. The amplification of these fragments were performed by using following primers; $\mathrm{ABCA} 3$-fragment A-F663 (5'TCAGACCACCTACTTCTCTAGCAGC-3'),

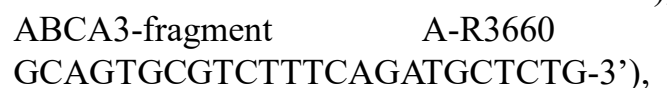
ABCA3-fragment B-F3446 (5'TTCCTGAAGAAGGCCGCATACAGC-3'), and ABCA3-fragment B-R5962 (5'CACTCGTCCATTCTGTGCATACTGC-3'). Each fragment was amplified using ReverTra Dash
(TOYOBO Co. Ltd., Osaka, Japan). The PCR conditions were as follows: initial denaturation in one cycle of $5 \mathrm{~min}$ at $95^{\circ} \mathrm{C}, 30$ cycles with $30 \mathrm{~s}$ at $95^{\circ} \mathrm{C}$ (denaturation), $30 \mathrm{~s}$ at $65^{\circ} \mathrm{C}$ (annealing), and 3 min at $72^{\circ} \mathrm{C}$ (extension). The purified fragment $\mathrm{A}$ and $\mathrm{B}$ were cloned into pIRESpuro2 Vector and pGEM-T Easy Vector, respectively. These plasmids were digested by Psh AI and Not I, and isolated fragment $\mathrm{B}$ was ligated into fragment A-containing vector by T4 DNA ligase, followed by pIRESpuro2 Vector containing full-length human $\mathrm{ABCA} 3$ gene. Finally, the plasmid was digested by EcoRI and ABCA3 gene isolated was cloned into EcoRI site of pMXs-Puro Retroviral Vector. Retrovirus infection into A549 cells was performed as reported previously (19). A549/ABCA3 cells were cultured in DMEM containing $10 \%$ FBS, $100 \mathrm{IU} / \mathrm{mL}$ penicillin, and $100 \mathrm{mg} / \mathrm{mL}$ streptomycin in an atmosphere of $5 \% \mathrm{CO}_{2} / 95 \%$ air at $37^{\circ} \mathrm{C}$, and subcultured every 7 days using $0.25 \%$ trypsin and $1 \mathrm{mM}$ EDTA. Fresh medium was replaced every $2-3$ days.

\section{Evaluation of mRNA expression}

A549/ABCA3 cells grown on 12-well plate were treated with BLM $(60 \mu \mathrm{M})$ and MTX $(0.3 \mu \mathrm{M})$ for $144 \mathrm{~h}$. Extraction of total RNA from the treated cells, the reverse transcription, and the amplification of the obtained cDNA were performed as reported previously (20). The primers were: sense 5'CGGGAAGACCACGACTTT-3', and antisense, 5'GCTGCCGCACCTTTC-3' for ABCA3; sense 5'AGATCTACCTGTACACCTTGAATGACA-3', and antisense, 5'-CCATGATACCAGCAAGGAATTG3' for fibronectin; sense 5'AGGAAAATGGCTGTTGGTATGATC-3', and antisense 5'-CGCAACTGCAAATGCCAG-3' for PEPT2. The primers for collagen type Ia 1 (COL1A1), $\alpha$-smooth muscle actin ( $\alpha$-SMA), and glyceraldehyde-3-phosphate dehydrogenase (GAPDH) were prepared as reported previously (20, 21). The expression level of mRNA was normalized as to that of GAPDH, a housekeeping gene.

\section{Confocal Laser Scanning Microscopy}

Staining of lamellar body and actin filaments were performed as reported previously $(19,20)$. Each florescence intensity in the cells was visualized by confocal laser scanning microscopy (CLSM) (OLYPUS FV1000D).

\section{Evaluation of miRNA expression}

A549/ABCA3 cells grown on 12-well plate were treated with BLM $(60 \mu \mathrm{M})$ and MTX $(0.3 \mu \mathrm{M})$ for $144 \mathrm{~h}$. Quantitative evaluation of miR-34a expression level by real-time PCR was performed 
using miScript Reverse Transcription Kit and miScript SYBR Green PCR Kit (QIAGEN, Hilden, Germany), as reported previously (14).

\section{Transfection with the miR-34a Mimic}

A549/ABCA3 cells grown on 12-well plates were transfected with $21 \mathrm{nM}$ of miRIDIAN microRNA miR-34a-5p-mimic or miRIDIAN microRNA Mimic Negative control (GE Healthcare Japan) using Lipofectamine ${ }^{\mathrm{TM}} 2000$ (Thermo Fisher Scientific Inc., Waltham, MA) for $24 \mathrm{hr}$. After $72 \mathrm{hr}$, total RNA was obtained from the treated cells.

\section{Preparation of cytoplasmic and nuclear protein extracts}

A549/ABCA3 cells grown on 100-mm culture dish were treated with BLM $(60 \mu \mathrm{M})$ and $\operatorname{MTX}(0.3 \mu \mathrm{M})$ for $12 \mathrm{~h}$. After that, preparation of cytoplasmic and nuclear protein extracts was performed as reported previously (22). Briefly, the treated cells were washed two times with PBS buffer, scraped, and collected by centrifugation at $500 \times \mathrm{g}$ for $5 \mathrm{~min}$ at $4^{\circ} \mathrm{C}$. Cell lysis was performed in ice-cold hypotonic lysis buffer (10 mM HEPES (pH 7.9), $10 \mathrm{mM} \mathrm{KCl}$, 1 mM EDTA, $1 \mathrm{mM}$ EGTA, $0.5 \mathrm{mM} \mathrm{Na}_{3} \mathrm{VO}_{4}, 0.5 \%$ v/v NP-40, 10\% v/v glycerol, $1 \mathrm{mM}$ dithiothreitol, 1 $\mathrm{mM}$ phenylmethanesulfonyl fluoride (PMSF)). Nuclear and cytoplasmic fractions were separated by centrifugation at $1000 \times \mathrm{g}$ for $5 \mathrm{~min}$ at $4^{\circ} \mathrm{C}$. The resulting supernatant (cytoplasmic fraction) was stored at $-80^{\circ} \mathrm{C}$ until further analysis. The membrane pellet was then resuspended in ice-cold hypertonic lysis buffer (20 mM HEPES (pH 7.9), $420 \mathrm{mM} \mathrm{NaCl}$, $1 \mathrm{mM}$ EDTA, $1 \mathrm{mM}$ EGTA, $500 \mu \mathrm{M} \mathrm{Na}_{3} \mathrm{VO}_{4}, 20 \%$ $\mathrm{v} / \mathrm{v}$ glycerol, $1 \mathrm{mM}$ dithiothreitol, $1 \mathrm{mM}$ PMSF), and incubated with shaking for $15 \mathrm{~min}$ at $4^{\circ} \mathrm{C}$. Soluble compounds were then isolated by centrifugation at $12000 \times \mathrm{g}$ for $5 \mathrm{~min}$ at $4^{\circ} \mathrm{C}$. The resulting supernatant (nuclear fraction) was stored at $-80^{\circ} \mathrm{C}$ until further analysis.

\section{Western Blotting}

Western blot analysis was performed as reported previously (21). Phospho-p53 (Ser15), p53, lamin $\mathrm{A} / \mathrm{C}$, and $\alpha$-tubulin were detected using antibodies against rabbit anti-phospho-p53 (Ser15) (1:250 dilution, Cell Signaling Technology, Inc), mouse anti-p53 (1:2000 dilution, Merck), Lamin $\mathrm{A}+\mathrm{C}$ (1:3000 dilution, Gene Tex), and alpha Tubulin 4a (1:5000 dilution, GeneTex), respectively.

\section{STATISTICAL ANALYSIS}

Data are expressed as the mean \pm standard error of the mean (S.E.M.). Statistical analysis was performed using one-way ANOVA followed by Tukey's test for multiple comparisons. A $p$ value $<$ 0.05 indicated significance.

\section{RESULTS}

\section{Establishment of A549/ABCA3 cells}

At first, we tried to establish the A549/ABCA3 cells as a novel type II alveolar epithelial cell line. So far, we established RLE/Abca3 cells by introducing rat abca3 gene into RLE-6TN cells and found that the increases in type II-like phenotypes of the cells were observed compared with those in the RLE/Vector cells (19). Therefore, A549/ABCA3 cells were prepared by introducing human $\mathrm{ABCA} 3$ gene into A549 cells with the same strategy to RLE/Abca3 cells as described in Materials and Methods. As presented in Figure 1A, the expression of both type II alveolar epithelium markers, ABCA3 and PEPT2, were markedly higher in A549/ABCA3 than in A549/Vector cells. Furthermore, LysoTracker ${ }^{\circledR}$ Red staining revealed that formation of lamellar bodylike structures was enhanced in A549/ABCA3 compared with A549/Vector cells (Figure 1B). These results suggested that type II-like phenotypes of A549/ABCA3 cells were enhanced compared with the wild type cells. Therefore, further examination was proceeded using newly established A549/ABCA3 cells.

EMT induction by various anticancer drugs in A549/ABCA3 cells

EMT-inducing effect of BLM and MTX, anticancer drugs having pulmonary toxic effect, on A549/ABCA3 cells was examined. As shown in Figure 2A, after treatment with these drugs for 144 $\mathrm{h}$, the morphology was drastically changed, and actin filaments assembled into contractile stress fibers were observed compared to the control. In addition, both drugs significantly enhanced mRNA expression level of $\alpha$-SMA, an EMT marker, while decreased that of ABCA3 (Figure 2B). Paclitaxel (PTX) and gefitinib (GEF) are also well-known to induce lung injury. Therefore, the effects of PTX and GEF on mRNA expression level of $\alpha$-SMA were examined. Notably, both drugs led to increase in mRNA expression of $\alpha$-SMA in A549/ABCA3 cells (Figure 2C).

\section{Role of miR-34a in drug-induced EMT process in A549/ABCA3 cells}

We already showed that miR-34a increased $\alpha$-SMA mRNA expression in RLE/Abca3 cells (14). Therefore, role of miR-34a in drug-induced EMT was also examined in A549/ABCA3 cells. BLM and 
MTX clearly upregulated the miR-34a expression in A549/ABCA3 cells (Figure 3A). In addition, expression level of miR-34a was also enhanced by PTX and GEF (Figure 3B). As miR-34a expression was closely associated with $\alpha$-SMA in drug-treated A549/ABCA3 cells, the contribution of miR-34a to $\alpha$-SMA expression was examined. As shown in Fig. $3 \mathrm{C}$, overexpression of miR-34a by introducing mimic of miR-34a into the cells enhanced the mRNA expression level of $\alpha$-SMA, indicating that miR-34a may induce EMT in A549/ABCA3 cells. Furthermore, miR-34a mimic introduction led to upregulation of mRNA expression levels of extracellular matrix components such as COL1A1 and fibronectin (Figure 3D), indicating that miR-34a may play an important role in production of extracellular matrix through the EMT process.

\section{Effects of BLM and MTX on phosphorylation of p53 at Ser15}

Generally, BLM and MTX cause DNA damage, followed by upregulation of $\mathrm{p} 53$. On the other hand, p53 regulates miR-34a expression by binding to the promotor region (16). Considering those facts, we hypothesized that drug-induced upregulation of miR-34a is associated with p53. At first, the effects of BLM and MTX on phosphorylation of $\mathrm{p} 53$ were examined using Phos-tag ${ }^{\circledR}$ SDS-PAGE system. Several phosphorylated p53 bands at different degree were observed, and all obtained bands tended to be high in nucleus than in cytoplasmic fraction. In both fractions, all bands were upregulated by the treatment of A549/ABCA3 cells with BLM and MTX (Figure 4A), indicating that both anticancer drugs may lead to upregulation of $\mathrm{p} 53$. Furthermore, using monoclonal antibody against phosphorylated p53 at Ser15, phosphorylation of Ser15 in nucleus fraction was upregulated by both drugs (Figure 4B), indicating that these anticancer drugs may lead to activation of $\mathrm{p} 53$ via phosphorylation of Ser15.
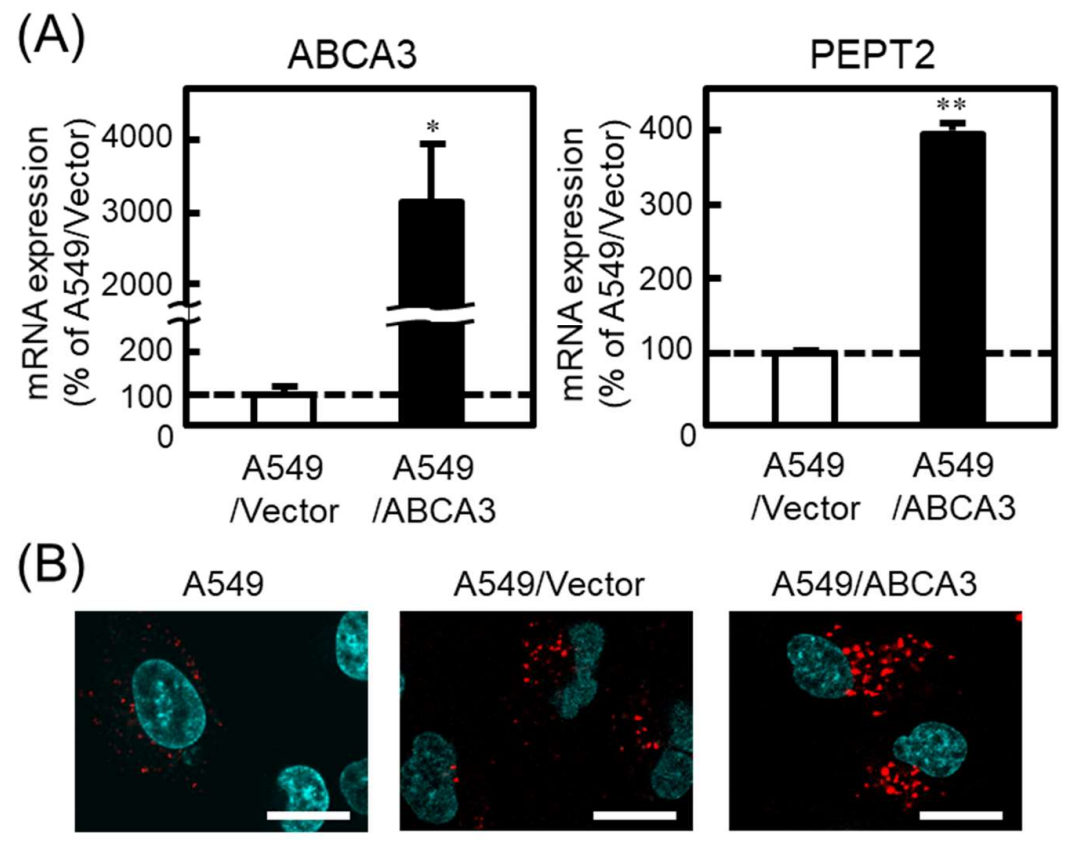

Blue; Nucleus, Red; lamellar bodies Scale bar: $20 \mu \mathrm{m}$

Figure 1. Characterization of A549/ABCA3 cells as a newly established type II alveolar epithelial cell line. A549 cells were transfected with retrovirus vector containing (A549/ABCA3) or not containing (A549/Vector) ABCA3 gene as described in Materials and Methods. (A) mRNA expression levels of ABCA3 and PEPT2, a type II alveolar epithelial marker, was measured by realtime PCR analysis. Each value represents the mean \pm S.E.M. $(n=3) . * p<0.05, * * p<0.01$; significantly different from A549/Vector cells. (B) Immuno fluorescence analysis for detection of lamellar body in A549, A549/Vector and A549/ABCA3 cells. The cells were treated with LysoTracker ${ }^{\circledR}$ Red (red) and Hoechst33342 (blue) for staining of lamellar body and nucleus, respectively. 
(A)

Control

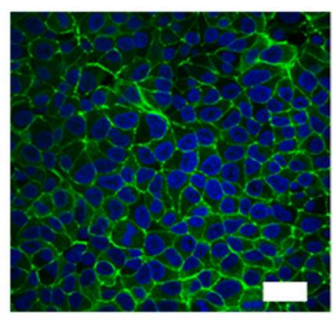

BLM

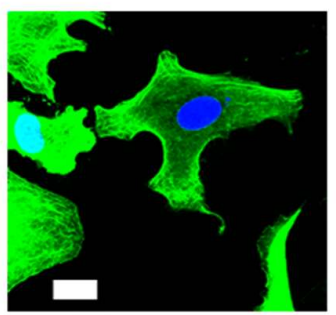

MTX

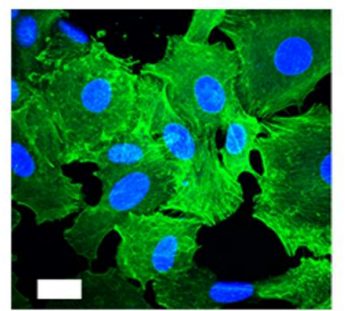

Blue; Nucleus, Green; actin filament Scale bar; $20 \mu \mathrm{m}$

(B)
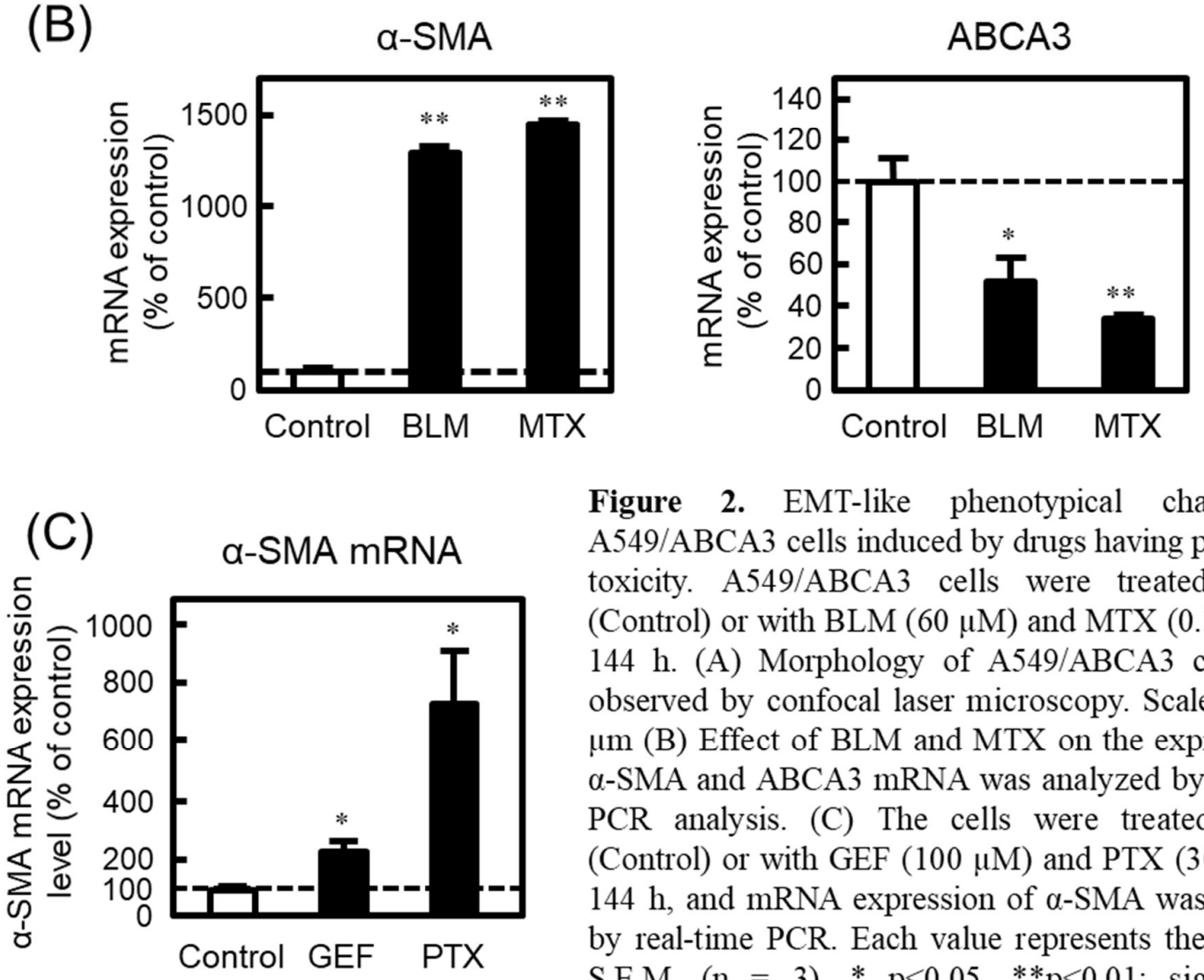

Figure 2. EMT-like phenotypical changes of A549/ABCA3 cells induced by drugs having pulmonary toxicity. A549/ABCA3 cells were treated without (Control) or with BLM $(60 \mu \mathrm{M})$ and MTX $(0.3 \mu \mathrm{M})$ for $144 \mathrm{~h}$. (A) Morphology of A549/ABCA3 cells were observed by confocal laser microscopy. Scale bars: 20 $\mu \mathrm{m}$ (B) Effect of BLM and MTX on the expression of $\alpha$-SMA and ABCA3 mRNA was analyzed by real-time PCR analysis. (C) The cells were treated without (Control) or with GEF $(100 \mu \mathrm{M})$ and PTX $(30 \mathrm{nM})$ for $144 \mathrm{~h}$, and mRNA expression of $\alpha$-SMA was analyzed by real-time PCR. Each value represents the mean \pm S.E.M. $(\mathrm{n}=3) .{ }^{*} \mathrm{p}<0.05,{ }^{* *} \mathrm{p}<0.01$; significantly different from Control.

\section{DISCUSSION}

Several reports have indicated that myofibroblastinduced ECM production would be one of critical factors in the development of pulmonary fibrosis (5, 6). During normal wound healing, resident fibroblasts are converted into active myofibroblasts, while EMT contributes to abnormal recruitment of myofibroblasts, followed by excessive ECM production in pathological conditions (11). In particular, type II alveolar epithelial cells are considered to be one of the sources for active myofibroblasts in the lung $(7,14)$. Therefore, suitable type II alveolar epithelium model has an advantage in appropriate understanding on EMT in clinical situation. In the present study, A549/ABCA3 cells were newly established as a type II alveolar epithelium model. So far, we experienced that Abca3 gene introduction conferred type II alveolar epithelium properties in RLE-6TN cells, with increases in mRNA expression level of PEPT2 and lamellar body formation (19), which were 
comparable to current results in A549/ABCA3 cells. On the other hand, we previously demonstrated that albumin transport capacity was higher in type II than in type I-like alveolar epithelial cells using primary cultured cells isolated from rat lung $(23,24)$. Although albumin transport in RLE/Abca3 cells was higher than that in the wild type cells in previous studies (19), there were no differences in function of albumin transport between A549/ABCA3 and the wild type cells (data not shown). Other factors may be needed to make A549/ABCA3 cells more validated model for type II alveolar epithelial cells.

In A549/ABCA3 cells, BLM, MTX, PTX, and GEF clearly induced EMT with increase in mRNA expression level of $\alpha$-SMA. However, differences in effects of EMT-inducing drugs on A549 and A549/ABCA3 cells have not been well examined. Actually, we used A549 cells for investigations on drug-induced EMT $(20,21)$, and observed similar EMT-like changes to the present study. On the other hand, ABCA3 plays an important role in regulation of pulmonary surfactant homeostasis in the alveoli (25). In A549/ABCA3 cells, mRNA expression level of $A B C A 3$ was suppressed by the treatment with

(A)

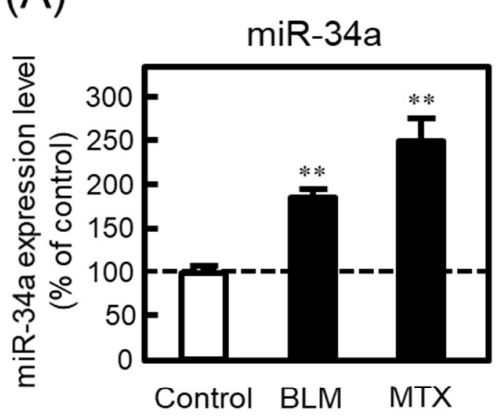

(C)

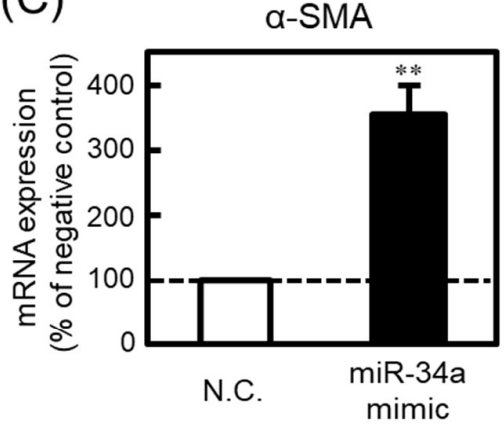

BLM and MTX. Therefore, ABCA3 may be considered to be a key factor associated with EMT and use of A549/ABCA3 cells may have advantage in terms of investigations on drug-induced lung injury.

BLM and MTX increased miR-34a expression level in A549/ABCA3 cells, indicating that common factors may be associated with drug-induced increase in expression level of miR-34a. According to the reports showing that both drugs enhanced p53 activity in A549 cells $(26,27)$, the upregulation of phosphorylated p53 by BLM and MTX was observed, which also corresponded to information on miR-34a upregulation mediated by p53 $(16,28)$. In addition, both drugs-induced increase in phosphorylation of Ser15 in p53 was observed. Nterminal phosphorylation at Ser15 has been generally known to stabilize p53 by inhibiting the interaction between p53 and MDM2, which is wellknown to be a negative regulator of p53 as an E3 ubiquitin ligase (29). Therefore, BLM and MTX may increase miR-34a expression by stabilizing p53 in A549/ABCA3 cells.

(B)

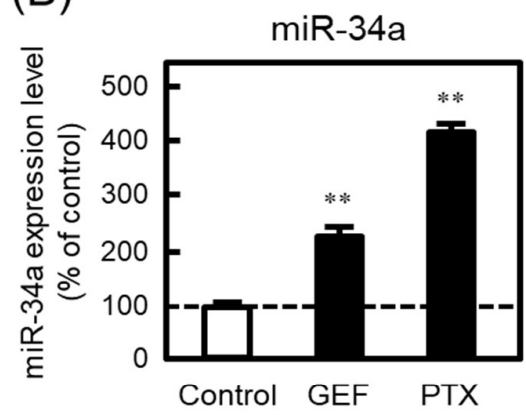

(D)

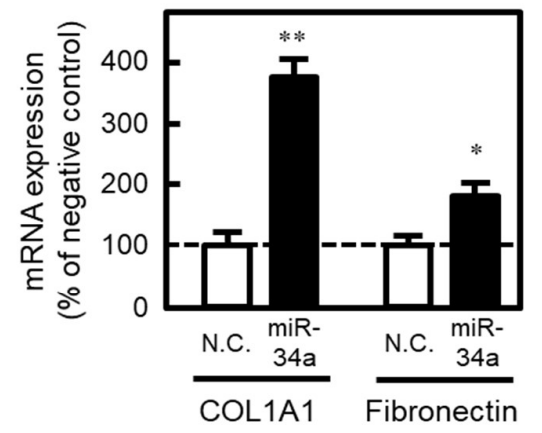

Figure 3. Role of miR-34a in BLM- and MTX-induced EMT. (A) A549/ABCA3 cells were treated without (Control) or with BLM $(60 \mu \mathrm{M})$ and MTX $(0.3 \mu \mathrm{M})$ for $144 \mathrm{~h}$. (B) The cells were treated without (Control) or with GEF $(100 \mu \mathrm{M})$ and PTX $(30 \mathrm{nM})$ for $144 \mathrm{~h}$. Expression level of miR-34a was measured by realtime PCR analysis. Each value represents the mean \pm S.E.M. $(n=3)$. $(C, D)$ The cells were transfected with negative control (N.C.) or miR-34a mimic $(21 \mathrm{nM}$ ) for $24 \mathrm{~h}$. After $72 \mathrm{~h}$, mRNA expression levels of $\alpha$ SMA (C), and COL1A1 and fibronectin (D) were measured by real-time PCR analysis. Each value represents the mean \pm S.E.M. $(n=3) .{ }^{*}<<0.05, * * p<0.01$; significantly different from Control or N.C. 


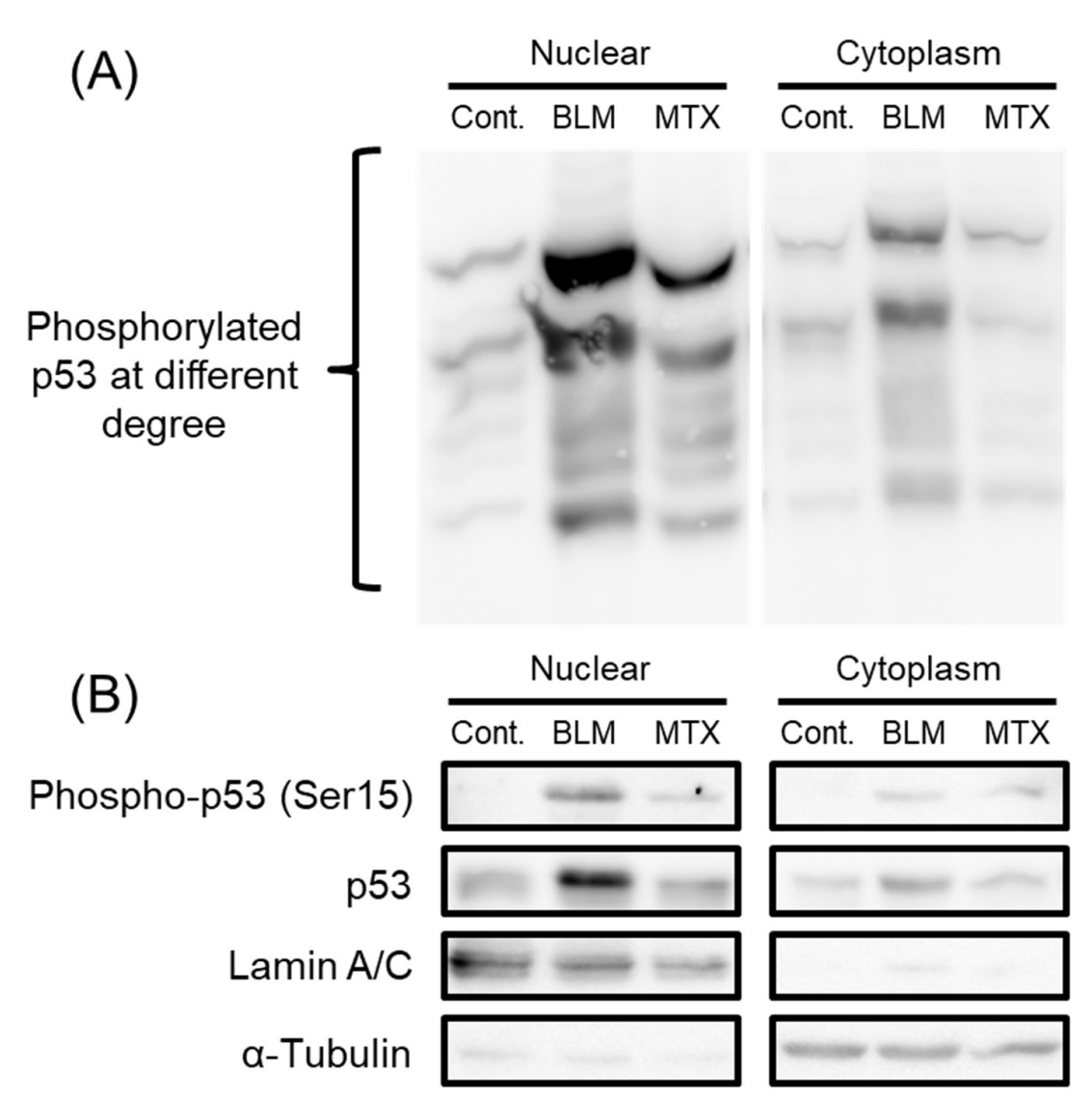

Figure 4. Involvement of p53/miR-34a axis in drug-induced EMT in A549/ABCA3 cells. A549/ABCA3 cells were treated without (Cont.) or with BLM $(60 \mu \mathrm{M})$ and MTX $(0.3 \mu \mathrm{M})$ for $12 \mathrm{~h}$. Nuclear and cytoplasmic fraction were prepared as described in Materials and Methods. Nuclear and cytoplasmic fractions $(30 \mu \mathrm{g} /$ well $)$ were subjected to (A) Phos-tag SDS-PAGE system containing $50 \mu \mathrm{M}$ Phos-tag ${ }^{\circledR}$ acrylamide and $100 \mu \mathrm{M} \mathrm{MgCl}{ }_{2}$ or (B) normal SDS-PAGE system. Phospho-p53 (Ser15), p53, Lamin A/C (Nuclear marker), and $\alpha$-Tubulin (cytoplasmic marker) in nuclear and cytoplasmic fraction were detected by western blot, respectively.

Taken together, using A549/ABCA3 cells, we clarified for the first time the significant relationship between drug-induced EMT and upregulation of p53 activity and miR-34a expression.

As miR-34a mimic introduction led to enhancement of $\alpha$-SMA mRNA expression level in A549/ABCA3 cells, miR-34a may have a capacity to promote EMT. However, underlying mechanism of miR-34a-induced EMT remains unclear at this moment. Several reports indicated that miR-34a inhibited EMT via direct suppression of Snail in colorectal and ovarian cancer cell lines $(30,31)$, and miR-34a is considered as a promising therapeutic agent for malignant tumors (32), which is the opposite information to our findings. Thus, the present study would provide new findings concerning the relationship between drug-induced EMT and miR-34a in alveolar epithelial cells. On one hand, it has been reported that miR-34a enhanced alveolar epithelial cell apoptosis and promoted BLM-induced pulmonary fibrosis in mice (33). Furthermore, we found that miR-34a mimic introduction increased mRNA expression level of COL1A1 and fibronectin in A549/ABCA3 cells, which are critical extracellular matrix components in pulmonary fibrosis, indicating that miR-34a may contribute to the development of pulmonary fibrosis. To clarify the net contribution of miR-34a to EMT process and pulmonary fibrosis, further studies should be required.

\section{CONCLUSION}

We established A549/ABCA3 cells as a novel type II alveolar epithelial cell model, observing increase in type II features such as mRNA expression level of 
PEPT2, a type II marker, and formation of lamellar bodies compared to wild-type A549 cells. In this model, the drugs having pulmonary toxicity including BLM, MTX, GEF, and PTX induced the remodeling of actin-filaments and increase in mRNA expression of $\alpha$-SMA, indicating that A549/ABCA3 cells would be useful for EMT studies. In addition, these drugs increased expression level of miR-34a, and introduction of miR-34a mimic into the cells led to induction of EMT, suggesting that drug-induced EMT in A549/ABCA3 cells may be associated with miR-34a. Furthermore, p53 was upregulated by BLM and MTX via increase in phosphorylation of p53 at Ser15. Taken together, A549/ABCA3 cells may be a useful cell model for studying EMT process in type II alveolar epithelia, and p53/miR-34a axis would be one of the therapeutic target for drug-induced lung injury.

\section{ACKNOWLEDGEMENT}

We appreciate Professor Tahara-H (Hiroshima University) and Professor Shimamoto-A (SanyoOnoda City University) for providing kind advises concerning establishment of A549/ABCA3 cells, and Professor Koike-T (Hiroshima University) for providing Phos-tag ${ }^{\circledR}$ Acrylamide. Also, we thank Ms. Yamamoto-C for her assistance in the establishment of A549/ABCA3 cells. This study was supported in part by the Grants-in-Aid for Scientific Research from the Japan Society for the Promotion of Science (JP18H02586, JP18K06749, and JP16K18945).

\section{CONFLICT OF INTEREST STATEMENT}

The authors declare that there are no conflicts of interest.

\section{REFERENCES}

1. Froudarakis M, Hatzimichael E, Kyriazopoulou L, Lagos K, Pappas P, Tzakos AG, Karavasilis V, Daliani D, Papandreou C, Briasoulis E, Revisiting bleomycin from pathophysiology to safe clinical use. Crit Rev Oncol Hematol, 2013;87:90-100. doi:10.1016/j.critrevonc.2012.12.003.

2. Barrera P, Laan RF, van Riel PL, Dekhuijzen PN, Boerbooms AM, van de Putte LB, Methotrexaterelated pulmonary complications in rheumatoid arthritis. Ann Rheum Dis, 1994;53:434-439. doi:10.1136/ard.53.7.434.

3. Selman M, King TE, Pardo A, American Thoracic Society, European Respiratory Society, American College of Chest Physicians, Idiopathic pulmonary fibrosis: prevailing and evolving hypotheses about its pathogenesis and implications for therapy. Ann Intern Med, 2001;134:136-151. doi:10.7326/00034819-134-2-200101160-00015

4. Wynn TA, Integrating mechanisms of pulmonary fibrosis. J Exp Med, 2011;208:1339-1350. doi:10.1084/jem.20110551.

5. Giannandrea M, Parks WC, Diverse functions of matrix metalloproteinases during fibrosis. Dis Model Mech, 2014;7:193-203. doi:10.1242/dmm.012062.

6. Goldmann T, Zissel G, Watz H, Drömann D, Reck M, Kugler C, Rabe KF, Marwitz S, Human alveolar epithelial cells type II are capable of TGF $\beta$ dependent epithelial-mesenchymal-transition and collagen-synthesis. Respir Res, 2018;19:138. doi:10.1186/s12931-018-0841-9.

7. Thiery JP, Acloque H, Huang RYJ, Nieto MA, Epithelial-mesenchymal transitions in development and disease. Cell, 2009;139:871-890. doi:10.1016/j.cell.2009.11.007.

8. Willis BC, Borok Z, TGF- beta -induced EMT : mechanisms and implications for fibrotic lung disease. Am J Physiol Lung Cell Mol Physiol, 2007;293:L525-34. doi:10.1152/ajplung.00163.2007.

9. Bartel DP, MicroRNAs: target recognition and regulatory functions. Cell, 2009;136:215-233. doi:10.1016/j.cell.2009.01.002.

10. Rajasekaran S, Rajaguru P, Sudhakar Gandhi PS, MicroRNAs as potential targets for progressive pulmonary fibrosis. Front Pharmacol, 2015;6:254. doi:10.3389/fphar.2015.00254.

11. Yang S, Banerjee S, de Freitas A, Sanders YY, Ding Q, Matalon S, Thannickal VJ, Abraham E, Liu G, Participation of miR-200 in pulmonary fibrosis. Am J Pathol, 2012;180:484-493. doi:10.1016/j.ajpath.2011.10.005.

12. Lino Cardenas CL, Henaoui IS, Courcot E, Roderburg C, Cauffiez C, Aubert S, Copin MC, Wallaert B, Glowacki F, Dewaeles E, Milosevic J, Maurizio J, Tedrow J, Marcet B, Lo-Guidice JM, Kaminski N, Barbry P, Luedde T, Perrais M, Mari B, Pottier N, miR-199a-5p is upregulated during fibrogenic response to tissue injury and mediates TGFbeta-induced lung fibroblast activation by targeting caveolin-1. PLoS Genet, 2019;9:e1003291. doi:10.1371/journal.pgen.1003291.

13. Marmai C, Sutherland RE, Kim KK, Dolganov GM, Fang X, Kim SS, Jiang S, Golden JA, Hoopes CW, Matthay MA, Chapman HA, Wolters PJ, Alveolar epithelial cells express mesenchymal proteins in patients with idiopathic pulmonary fibrosis. Am J Physiol Cell Mol Physiol, 2011;301:L71-L78. doi:10.1152/ajplung.00212.2010.

14. Takano M, Nekomoto C, Kawami M, Yumoto R, Role of miR-34a in TGF- $\beta 1$ - and drug-induced 
epithelial-mesenchymal transition in alveolar type II epithelial cells. J Pharm Sci, 2017;106:2868-2872. doi:10.1016/j.xphs.2017.04.002.

15. Takano M, Yamamoto C, Yamaguchi K, Kawami M, Yumoto R, Analysis of TGF- $\beta 1$ - and drug-induced epithelial-mesenchymal transition in cultured alveolar epithelial cell line RLE/Abca3. Drug Metab Pharmacokinet, 2015;30:111-118. doi:10.1016/j.dmpk.2014.10.007.

16. He L, He X, Lim LP, de Stanchina E, Xuan Z, Liang Y, Xue W, Zender L, Magnus J, Ridzon D, Jackson AL, Linsley PS, Chen C, Lowe SW, Cleary MA, Hannon GJ, A microRNA component of the p53 tumour suppressor network. Nature, 2007;447:11301134. doi:10.1038/nature05939.

17. Lee YS, Yoon S, Park MS, Kim JH, Lee JH, Song $\mathrm{CW}$, Influence of p53 expression on sensitivity of cancer cells to bleomycin. J Biochem Mol Toxicol, 2010;24:260-269. doi:10.1002/jbt.20334.

18. Fekry B, Esmaeilniakooshkghazi A, Krupenko SA, Krupenko NI, Ceramide synthase 6 is a novel target of methotrexate mediating its antiproliferative effect in a p53-dependent manner. PLoS One, 2016;11:e0146618. doi:10.1371/journal.pone.0146618.

19. Takano M, Yamamoto C, Sambuichi K, Oda K, Nagai J, Shimamoto A, Tahara H, Yumoto R, Introduction of a single transporter gene ABCA3 directs RLE-6TN to more type II-like alveolar epithelial cells. Membrane, 2013;38:246-253.

20. Kawami M, Harabayashi R, Harada R, Yamagami Y, Yumoto R, Takano M, Folic acid prevents methotrexate-induced epithelial-mesenchymal transition via suppression of secreted factors from the human alveolar epithelial cell line A549. Biochem Biophys Res Commun, 2018;497:457-463. doi:10.1016/j.bbrc.2018.02.111.

21. Kawami M, Harabayashi R, Miyamoto M, Harada R, Yumoto R, Takano M, Methotrexate-induced epithelial-mesenchymal transition in the alveolar epithelial cell line A549. Lung, 2016;194:923-930. doi:10.1007/s00408-016-9935-7.

22. Milosevic J, Bulau P, Mortz E, Eickelberg O, Subcellular fractionation of TGF- $\beta 1$-stimulated lung epithelial cells: A novel proteomic approach for identifying signaling intermediates. Proteomics, 2009;9:1230-1240. doi:10.1002/pmic.200700604.

23. Ikehata M, Yumoto R, Nakamura K, Nagai J, Takano $\mathrm{M}$, Comparison of albumin uptake in rat alveolar type II and type I-like epithelial cells in primary culture. Pharm Res, 2008;25:913-922. doi:10.1007/s11095007-9426-x.

24. Takano M, Kawami M, Aoki A, Yumoto R, Receptor-mediated endocytosis of macromolecules and strategy to enhance their transport in alveolar epithelial cells. Expert Opin Drug Deliv, 2015; $12: 813-825$. doi:10.1517/17425247.2015.992778.

25. Besnard V, Matsuzaki Y, Clark J, Xu Y, Wert SE, Ikegami M, Stahlman MT, Weaver TE, Hunt AN, Postle AD, Whitsett JA, Conditional deletion of Abca3 in alveolar type II cells alters surfactant homeostasis in newborn and adult mice. Am J Physiol Lung Cell Mol Physiol, 2010;298:L646-659. doi:10.1152/ajplung.00409.2009.

26. Linge A, Weinhold K, Bläsche R, Kasper M, Barth $\mathrm{K}$, Downregulation of caveolin-1 affects bleomycininduced growth arrest and cellular senescence in A549 cells. Int J Biochem Cell Biol, 2007;39:19641974. doi:10.1016/j.biocel.2007.05.018.

27. Huang WY, Yang PM, Chang YF, Marquez VE, Chen $\mathrm{CC}$, Methotrexate induces apoptosis through p53/p21-dependent pathway and increases Ecadherin expression through downregulation of HDAC/EZH2. Biochem Pharmacol, 2011;81:510 517. doi:10.1016/j.bcp.2010.11.014.

28. Wang B, Li D, Kovalchuk O, p53 Ser15 phosphorylation and histone modifications contribute to IR-induced miR-34a transcription in mammary epithelial cells. Cell Cycle, 2013;12:2073-2083. doi:10.4161/cc.25135.

29. Kruse J-P, Gu W, Modes of p53 Regulation. Cell, 2009;137:609-622. doi:10.1016/j.cell.2009.04.050.

30. Siemens H, Jackstadt R, Hünten S, Kaller M, Menssen A, Götz U, Hermeking H, miR-34 and SNAIL form a double-negative feedback loop to regulate epithelial-mesenchymal transitions, Cell Cycle, 2011;10:4256-4271. doi:10.4161/cc.10.24.18552.

31. Dong P, Xiong Y, Watari H, Hanley SJB, Konno Y, Ihira K, Yamada T, Kudo M, Yue J, Sakuragi N, MiR-137 and miR-34a directly target Snail and inhibit EMT, invasion and sphere-forming ability of ovarian cancer cells. J Exp Clin Cancer Res, 2016;35:132. doi:10.1186/s13046-016-0415-y.

32. Nie D, Fu J, Chen H, Cheng J, Fu J, Nie D, Fu J, Chen $\mathrm{H}$, Cheng J, Fu J, Roles of microRNA-34a in epithelial to mesenchymal transition, competing endogenous RNA sponging and its therapeutic potential. Int J Mol Sci, 2019;20:861. doi:10.3390/ijms20040861.

33. Shetty SK, Tiwari N, Marudamuthu AS, Puthusseri B, Bhandary YP, Fu J, Levin J, Idell S, Shetty S, p53 and miR-34a feedback promotes lung epithelial injury and pulmonary fibrosis. Am J Pathol, 2017;187:1016-1034. doi:10.1016/j.ajpath.2016.12.020. 